\title{
CIRCUMVALLATE PLACENTA COMPLICATING TO PRETERM PREMATURE RUPTURE OF MEMBRANES: A CASE REPORT
}

\author{
Dr. Badal Das ${ }^{1}$, Dr. Krishna Pada Das ${ }^{2}$, Dr. Rajiv Ranjan Das ${ }^{6}$, Dr. Debobroto Roy ${ }^{3}$, Dr. Malay Sarkar ${ }^{4}$, Dr. Arpita \\ Pramanik $^{5}$ \\ ${ }^{1-5}$ Department of Obstetrics and Gynecology, Burdwan Medical College \& Hospital, Burdwan, West Bengal, India \\ ${ }^{6}$ Department of Pharmacology, Rajendra Institute of Medical Sciences, Ranchi, Jharkhand, India
}

\begin{abstract}
Circumvallate placenta, a morphological abnormality of placenta can be defined as a thickened placenta with a raised margin in an annular shape and it is thought to be the result of a membranous fold of chorion and amnion. A 23-year-old primigravida mother was presented with grossly reduced liquor due to preterm premature rupture of membranes at 32 weeks of gestation. The preterm baby was delivered by emergency caesarean section (category-2 caesarean section). A thorough gross examination of the placenta was done and a thickened circumvallate placenta was noted with a firm white annular margin and normal umbilical cord insertion. Histopathological findings were consistent with the diagnosis of circumvallate placenta. Routine gross examination of placenta is of immense important for better understanding of pregnancy complications due to placental abnormalities like circumvallate placenta.
\end{abstract}

Keywords-Amnion; Chorion; Circumvallate placenta.

\section{INTRODUCTION}

Circumvallate placenta, a morphological abnormality of placenta can be defined as a thickened placenta with a raised margin in an annular shape and it is thought to be the result of a membranous fold of chorion and amnion [1]. Its prevalence is estimated to be $1-7 \%$ [2]. Here the chorionic plate is smaller than the basal plate leading to an area of uncovered placenta where antepartum bleedings may occur [3]. Circumvallate placenta may be associated with preterm premature rupture of the membranes, vaginal bleeding, preterm delivery, and placental abruption and emergency cesarean section is often needed. Some fetal and neonatal complications like intrauterine growth restriction, neonatal death or admission to neonatal intensive care units are also more common in circumvallate placenta $[4,5,6]$.

\section{CASE REPORT}

A 23-year-old primigravida mother was referred from a rural hospital as a case of preterm premature rupture of membranes (PPROM) at 32 weeks of gestation. On admission in our hospital the patient's vitals were stable and per abdominally uterus was 28 weeks size, fetal heart rate was $146 /$ minutes; on per vaginal examination os-1.5 cm dilated, upper part of cervix was taken up and there was active dribbling. An urgent ultrasonography was performed which showed grossly reduced liquor with DVP-0.5 cm and an emergency caesarean section (category 2) was performed. The baby was born with birth weight of $1980 \mathrm{gm}$ and Apgar score of 8/9/9 at 1, 5 and 10 minutes respectively. A thorough gross examination of the placenta was done and a thickened circumvallate placenta was noted with a firm white annular margin and normal umbilical cord insertion (Figure 1). The histopathological examination revealed an arrest of placental villi ripening, an amnion nodosum with increased growth of stromal syncytial buds.

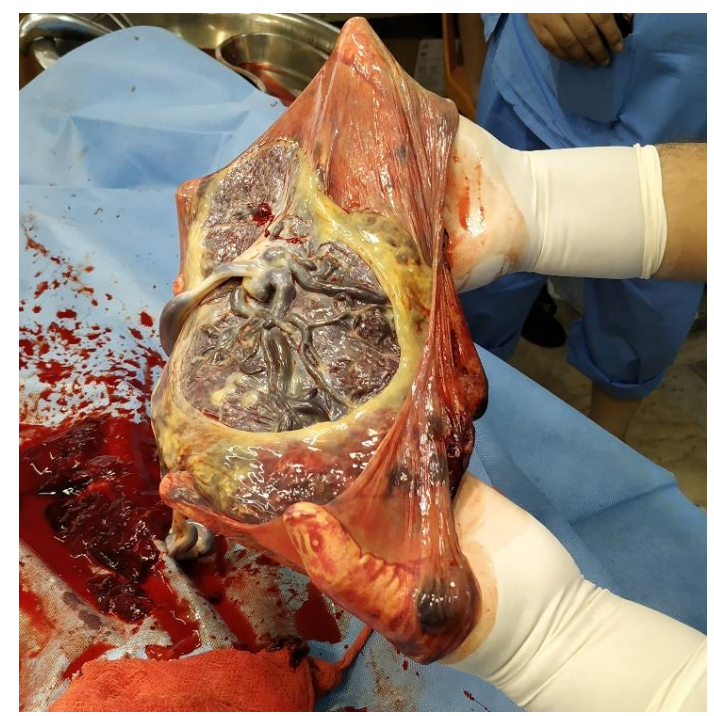

Figure 1: Circumvallate placenta with a firm white annular margin 
International Journal of Engineering Applied Sciences and Technology, 2021

Vol. 6, Issue 5, ISSN No. 2455-2143, Pages 170-171

Published Online September 2021 in IJEAST (http://www.ijeast.com)

\section{DISCUSSION}

We report this case because of its rarity and its potentiality to cause several pregnancy complications like PPROM as in our case. It was diagnosed retrospectively by gross examination of the placenta after delivery. Although it is possible to diagnose circumvallate placenta prenatally by $2 \mathrm{D}$ or 3D ultrasonography, the accuracy is significantly limited. Routine examination of placenta after delivery is of paramount importance in diagnosing the circumvallate placenta.

\section{CONCLUSION}

A thorough gross examination of the placenta after delivery should be a routine practice as it can diagnose several placental morphological abnormalities like circumvallate placenta and help us in better understanding the complicating cause of placental abnormalities.

\section{DECLARATION}

Authors' contribution: Dr. B. Das has written the manuscript, collected the references and has done the gross examination of the placenta, Dr. K.P.Das, Dr. D. Roy and Dr. M. Sarkar performed the operation, Dr. R.R.Das and Dr. A. Pramanik collected the image and informed consent from the patient. All the authors finally read the manuscript and approved for submission for publication after doing necessary correction.

Funding: No funds were granted to support the present study.

Conflict of interest: The authors have no conflict interests hereby to declare.
Consent: Written informed consent was obtained from the patient for publication of this case report and accompanying image.

Ethical approval: Ethical Approval was not needed as we are not sharing any vital records and it is totally anonymous.

\section{REFERENCE}

[1] Bumm E. Grundriss zum Studium der Geburtshilfe. München: J.F. Bergmann-Verlag; 1922.

[2] Fox H, Elston CW. Pathology of the placenta. Major Probl Pathol. 1978;7:1-491.

[3] Williams JW. Placenta circumvallata. Am J Obstet Gynecol.1927;13:1-16.

[4] Rolschau J. Circumvallate placenta and intrauterine growth retardation. Acta Obstet Gynecol Scand Suppl. 1978;72:11-4.

[5] Taniguchi H, Aoki S, Sakamaki K, Kurasawa K, Okuda M, Takahashi $\mathrm{T}$, et al. Circumvallate placenta: associated clinical manifestations and complications-a retrospective study. Obstet Gynecol Int. 2014. https://doi.org/10.1155/2014/986230.

[6] Suzuki S. Clinical significance of pregnancies with circumvallate placenta. J Obstet Gynaecol Res. 2008;34:51-4. 